\title{
Additive Particles under Stress
}

\author{
Manfred Krifka* \\ University of Texas at Austin
}

\section{Introduction}

It is customary to identify three broad classes of grading particles: additive particles like also, exclusive particles like only, and scalar particles like even (cf. König (1991); in the examples, grave accent stands for the main, falling accent):
a. Peter also invited Pia for dinner.
'Peter invited Pia for dinner (and he invited someone else)'
b. Peter only invited Pia for dinner.
'(Peter inivited Pia for dinner, and) he invited no-one else.'
c. Peter even invited Pia for dinner.
'Peter invited Pia for dinner (and Pia is an unlikely person for Peter to invite for dinner).'

Additive particles are so-called because they express that the predication holds for at least one alternative of the expression in focus (here, Pia). This is presupposed; for example, it remains an entailment when the sentence is put in the scope of a modal expressing possibility, as in It may be that Peter also invited Pi ${ }_{\mathrm{F}}$ for dinner. In (1), I added the presupposed parts in parentheses (cf Horn (1969) for presupposition and assertion of grading particles). Exclusive particles presuppose that the predication holds for the expression in focus, and assert that it does not hold for any alternative. Scalar particles assert that the predication holds for the expression in focus, and presuppose that this predication is prima facie less likely than the alternative predications. We can represent things schematically as follows:

$$
\begin{array}{lll}
\text { a. } & {\left[\operatorname{ADD}_{1}\left[\ldots \mathrm{F}_{1} \ldots\right]\right]:} & {[\ldots \mathrm{F} \ldots]^{1}\left(\exists \mathrm{F}^{\prime} \neq \mathrm{F}\left[\ldots \mathrm{F}^{\prime} \ldots\right]\right)} \\
\text { b. }\left[\operatorname{EXCL}_{1}\left[\ldots \mathrm{F}_{1} \ldots\right]\right]: & \neg \exists \mathrm{F}^{\prime} \neq \mathrm{F}\left[\ldots \mathrm{F}^{\prime} \ldots\right]([\ldots \mathrm{F} \ldots]) \\
\text { c. }\left[\operatorname{SCAL}_{1}\left[\ldots \mathrm{F}_{1} \ldots\right]\right]: & \left.[\ldots \mathrm{F} \ldots]\left(\neg \exists \mathrm{F}^{\prime} \neq \mathrm{F}[\ldots \mathrm{F} \ldots]<_{\text {likely }}\left[\ldots \mathrm{F}^{\prime} \ldots\right]\right]\right)
\end{array}
$$

$\mathrm{F}$ stands for the expression in focus which is typically marked by accent; as it is not always marked by accent, I will call it, more neutrally, the associated constituent. [...F...] stands for the scope of the particle. I have assumed for simplicity that the particle has clausal scope; for particles with other scopes we have to work with type-shifted versions. $F^{\prime}$ ranges over alternatives of $F$ that are semantically of the same type as F, and may be contextually further restricted. The relation $<_{\text {likely }}$ between propositions says that one proposition is considered less likely than the other, at least with respect to the assumptions of the hearer before the current sentence is uttered. I do not distinguish between expressions and their meaning here, and I also disregard technical points like how focus information should be represented. Also, I assume that particles are coindexed with their focus.

The three classes of particles can be identified in a wide range of languages. However, there are interesting differences in their distribution that are also attested cross-linguistically. This paper deals with the following fact: While exclusive and scalar particles typically precede their focus, additive particles may follow it, in which case they are stressed. English has specialized additive particles too and as well that occur in this configuration:

Peter invited Pia for dinner, tòo / as wèll. 
Similar in French, which appears not to have any preposed additive particle, in Czech and in Hebrew:
a. $\left\{\right.$ Seule ${ }^{2} /$ Même / *Aussi $\}$ Marie est venue. ' $\{$ only / even / also\} Mary came.'
b. Marie est venue $\left\{*^{*}\right.$ seule $^{3} / *_{\text {même / aussi }\}}$
a. \{Jenom / Také\} Petr přšel. '\{only / also \} Petr came.'
b. Petr přšlel $\{*$ jenom / také\}.
a. \{Rak / Afilu / Gam\} Dani ba. ' $\{$ only / even / also\} Dani came.'
b. Dani ba $\left\{*_{\text {rak / *afilu / gam }\}}\right.$

In Swahili, both exclusive and additive particles occur in final position. But the exclusive particle $t u$, a one-syllable word, cannot be stressed, whereas additive particles like pia, tena and vilevile have two or more syllables and are always stressed:

a. Zebabu amekuja $\{$ tu / pia $\}$.

\{Only / also \} Zebabu has come.

I will concentrate in this article on German. In this language, all particles can follow their focus, but this is presumably due to the fact that the focused expressions can undergo certain types of movement, especially to the sentence-initial position. The basic and derived order is illustrated with examples (8.a) and (b).
a. Es hat [\{nur / auch / sogar $\}$ [Pèter ${ }_{\mathrm{F}}$ die Ausstellung besucht $\left.]\right]$. EXPLETIVE has \{only / also / even \} Peter the exhibition visited 'Only / also / even Pèter visited the exhibition.'
b. $\left[\left[\text { Pèter }_{\mathrm{F}}\right]_{1}\left[\text { hat }\left[\{\text { nur / auch / sogar }\}\left[\mathrm{t}_{1} \text { die Ausstellung besucht }\right]\right]\right]\right]^{4}$

But we find pattern (3), with stressed particle, only for the additive particle auch:

Peter hat die Ausstellung $\{$ àuch/*nùr/sogàr $\}$ besucht.

'Peter visited the exhibition, too.'

This is in spite of the fact that accent on nur is possible if the meaning of nur is highlighted. Notice that nur in (10) associates with gesungen, not with Peter.

(10) Pia hat gesungen und getanzt, und Peter hat nùr gesungen.

'Pia sang and danced, and Peter ònly danced.'

The pattern is not restricted to nur, sogar and auch. Other exclusive, scalar and additive particles behave in the same way (cf. Altmann (1976)).
a. *Peter hat die Ausstellung \{nùr / blòß / lèdiglich / àusschließlich / einzig und àllein $\}$ besucht.
b. *Peter hat die Ausstellung \{sogàr / sèlbst $\left.{ }^{5}\right\}$ besucht.
c. Peter hat die Ausstellung \{àuch / glèichfalls / èbenfalls \} besucht.

Evidence for the exclusion of scalar particles also comes from the following phenomenon, observed by Altmann (1976: p. 299). The particle auch has a scalar use which is prominent in (12.a), but this interpretation disappears in (b).

a. Auch der schnèllste Computer kann diese Aufgabe nicht lösen. 'Even the fastest computer cannot solve this task.'

b. Der schnellste Computer kann diese Aufgabe àuch nicht lösen.

'The fastest computer cannot solve this task, either.' 
The question that I want to address in this article is why we find only additive particles in the pattern illustrated in (3) and (9). To answer this, we first must explain how additive particles under stress identify their associated constituent.

\section{The Associated Constituent of Stressed Additive Particles}

\subsection{The Contrastive Topic Hypothesis}

One very common way how stressed additive particles identify their associated constituent is by secondary (rising) accent (indicated here by acute accent).

a. Péter hat die Ausstellung wahrscheinlich àuch besucht. 'Péter probably visited the exhibition, tòo''

b. Peter hat die Ausstellung wahrscheinlich àuch besucht. 'Peter probably visited the exhibítion, tòo.'

This is the same accentual pattern that we find in sentences with contrastive topics. ${ }^{6}$ Consider example (14). The context of (a) suggests that Peter is a contrastive topic, with a comment focus on die Ausstellung. The context of (b) suggests that die Ausstellung is a contrastive topic, with a comment focus on Peter. The contrastive topic is marked by a rising accent, and the focus of the comment is marked by a falling accent - the same prosodic pattern we observed in (13).

a. [What did Peter and Pia do in Houston?]

Péter hat die Àusstellung besucht (und Pia ist èinkaufen gegangen).

'Péter visited the èxhibition, (and Pía went shòpping).'

b. [Who visited the exhibition, and who went shopping?]

Die Ausstellung hat Pèter besucht (und éinkaufen ist Pì gegangen).

Contrastive topics are topics - they refer to something about which information is required. But they are also contrastive, that is, they come with alternatives there are other things about which information is required. The contrastive topic accent indicates the presence and the nature of these alternatives. We will analyze the pragmatic function of contrastive topics later in greater detail (cf. section 3). Let me now formulate our central hypothesis:

Contrastive Topic Hypothesis:

The associated constituent of stressed postposed additive particles is the contrastive topic of the clause in which they occur.

This hypothesis has been proposed by Kowalski (1992). Also, Altmann (1976), Jacobs (1983) and Koktová (1987) have suggested that there are parallels between the contrastive topic construction and sentences with stressed additive particles.

\subsection{Basic observations}

The Contrastive Topic Hypothesis was initially motivated by the fact that sentences like (13) exhibit a similar stress pattern as sentences with bona fide contrastive topics, like (14). It is also initially quite plausible, as the associated constituent of sentences with stressed additive particles occur naturally as contrastive topics:

[I know that Pia visited the exhibition. But what did Peter do?]

Péter hat die Ausstellung àuch besucht.

'Péter visited the exhibition, tòo.'

If our hypothesis is right, we expect that contexts in which the associated constituent cannot be a contrastive focus result in ungrammaticality. Unfortunately this is 
not easy to test because speakers can enrich contexts to accomodate a contrastive focus interpretation. But consider (17) (cf. also Koktová 1987: p.185f):
A: Ich hab gehört, ihr seid nach Itálien gefahren. Seid ihr sonst noch wohin gefahren?
'I heard you went to Italy. Did you go anywhere else?'
B: Wir sind auch nach Griechenland gefahren.
'We also went to Greece.'
B': 'Nach Griechenland sind wir àuch gefahren.

In the context of A's question, the travel destination should be (part of) the comment, and not a topic (even if contrastive). This explains the naturalness difference between B and B': In B, nach Griechenland is the focus of the comment, which is natural for a question that asks for a travel destination. In $\mathrm{B}^{\prime}$, nach Griechenland is a contrastive topic, which is unnatural in this context. But $\mathrm{B}^{\prime}$ is not completely out, as A's question can be asked with a background context in mind in which countries are possible discourse topics. This can be made explicit, for example, by enriching A's question to 'Speaking of Mediterranean countries, I have heard that you went to Italy. Did you go anywhere else?' In this type of context, $\mathrm{B}^{\prime}$ ' is fine.

\subsection{Multiple Topics}

Reis \& Rosengren (1997) argue against the contrastive topic hypothesis by showing that a sentence may contain other topics besides the associated constituent.
A: Mensch, Paul besitzt einen Gauguin. 'Boy, Paul owns a Gauguin painting.'
B: Einen Gauguín hat Peter àuch, aber keine anderen Impressionisten. 'Peter has a Gauguin too, but no other impressionistic paintings.'

Peter is a topic, and hence einen Gauguin cannot be a topic, Reis \& Rosengren argue. But the premise that a sentence can have only one topic is wrong. We can assume that in the context of B's answer, two sets of entities play a role as possible topics: first, persons (including Peter, Paul and perhaps others), and second, paintings. Then both Peter and einen Gauguin have to count as topics in (18). There are contexts in which the presence of two topics, even two contrastive topics, is clearly motivated:

\section{A: What about Peter and Pia? Did they get any gifts from Mary or Sue? \\ B: Pia hat von Máry einen Bàll geschenkt bekommen. 'Pía received from Máry a bàll.'}

There is one important fact about double topic constructions like (19). The topics are not ranked equally; rather, one topic has "scope" over the other one. To see this, notice first that there are cases with double focus in which both foci are treated on a par, as in (20) (called complex focus in Krifka (1992)).

[Peter introduced John to Mary, and] he also introduced Bíll to Sùe.

Such cases involve association of an opereator with a pair of foci:

$$
\left[\operatorname{ADD}_{1,2}\left[\ldots \mathrm{F}_{1} \ldots \mathrm{F}_{2} \ldots\right]\right]:\left[\ldots \mathrm{F}_{1} \ldots \mathrm{F}_{2} \ldots\right]\left(\exists \mathrm{F}_{1}^{\prime} \neq \mathrm{F}_{1} \exists \mathrm{F}_{2}^{\prime} \neq \mathrm{F}_{2}\left[\ldots \mathrm{F}_{1}^{\prime} \ldots \mathrm{F}_{2}^{\prime} \ldots\right]\right)
$$

But it seems that there are no "complex topics". This is quite plausible if the function of topic marking is to anchor a piece of information to the representation of a particular discourse entity. However, what we do find, and what cases like (19) exemplify, are stacked topics. That is, the speaker selects one discourse entity as a main topic at which a piece of information is to be stored, but structures this piece of information further into a secondary topic and a comment. 
If there are no complex topics, and if postposed additive particles under stress associate with contrastive topics, then we should assume that they can associate only with one constituent, and not with two. This should contrast with the regular case of additive particles, which can associate with a complex focus (cf. (20)). An observation along these lines has been made for English too by Green (1973), cf. also Kaplan (1984). They discuss contrasts like the following:
a. Jo had fish and Mo had fish too.
b. Jo had fish and Jo had soup too.
c. *Jo had fish and Mo had soup too'.

This contrast can be explained if we assume that postposed too associates with a contrastive topic (Mo in (22.a) and soup in (22.b)), but that there cannot be two contrastive topics of equal rank (Mo and soup in (22.c)). We should expect that preposed additive particles do not lead to this problem. This is the case, even though it cannot be easily tested with minimal variants of (22), as also in sentenceinitial position would be understood as having only the subject as focus. However, notice the following variant of the grammatical (20), which is equally bad as (22.c).

?? Peter introduced John to Mary, and] he introduced Bill to Susan too.

The contrast between (20) and (23) then supports the contrastive topic hypothesis.

\subsection{Additional Observations}

There are two additional observations that are explained under the Contrastive Topic Hypothesis. First, Altmann (1976: p. 261) shows that associated constituents that are syntactically complex often lead to a marked decline in acceptability:
a. Nixon nahm auch auf die ohnmächtige Öffentlichkeit im eigenen Lànd keine Rücksicht.
'Nixon also did not take the powerless public in his own country into consideration'
b. 'Auf die ohnmächtige Öffentlichkeit im eigenen Lánd nahm Nixon àuch keine Rücksicht.

The sentence-initial constituent of (24.b) is a bad topic not only because it is complex, but also because it is preferably read as containing an assertion, namely, that the public was powerless. And this contradicts the role of topics as identifying an entity at which a piece of information should be stored, for which presupposed information should be used.

Second, Altmann observes that associated constituents of stressed additive particles seldom occur in the so-called middle field, that is, following the finite verb (p. 259). This is just a tendency, as this position is possible, cf. (25).

Die Ausstellung hat Péter wahrscheinlich àuch besucht.

'Peter, too, probably visited the exhibition.'

But cases like that are rare. We can interpret the tendency observed by Almann by appealing to the known tendency of topics, including contrastive topics, to occur in sentence-initial position.

\subsection{Non-stressable Associated Constituents}

The rising accent of the topic constituent is not always easily audible. This is a consequence of the nature of prosodic marking, which makes use of non-discrete marking dimensions like pitch and amplitude. But there are certain cases in which focus induces a segmental change: Many languages distinguish between weak and 
strong pronouns, where focus on a pronoun requires the strong form. In German we find this distinction in one instance: The neuter personal pronoun es tends to be replaced by the demonstrative pronoun das when accented.

[What about the muesli?]

Peter mag auch $\{$ dàs / ?? ès\} nicht.

'Peter doesn't like that, either.'

If the associated constituent of stressed additive particles is a contrastive topic, and if contrastive topics involve focus, then we should expect a similar preference for das over es. Now, we indeed find the following distribution if we change (26) to a sentence with stressed auch:

\section{$\{$ Das / *Es\} mag Peter àuch nicht.}

But es in object function is never possible in sentence-initial position. While this might well be motivated by the fact that es is a weak pronoun and the sentenceinitial position must be motivated by focus for non-subjects, the severity of the violation in (27) suggests a grammaticized constraint against es in this position. So let us consider cases in which es remains in the middle field:

Weil Peter $\{$ das / es $\}$ wahrscheinlich àuch nicht mag.

For three of six speakers the intended reading (with the pronoun as associated constituent) was much easier with das than with es. But as the other three speakers pointed out, es is possible in contexts that provide for a contrastive topic interpretation of the antecedent of es, for example if (28) answers the following question:

Da Peter keinen Spinat ißt, warum hast du ihm nicht ein Müsli vorgesetzt?

'As Peter doesn't eat spinach, why didn't you serve him some muesli?'

Cases like this do not falsify the Contrastive Topic Hypothesis, as the referent of es in (28) clearly is a contrastive topic when uttered in the context of (29). They do, however, show that a contrastive topics need not be marked by accent.

The requirement that the associated constituent be a stressed form is relaxed even further if it is a subject. Sentences like (30.a,b) are generally accepted:

a. $\{$ Es / das $\}$ ist wahrscheinlich àuch runtergefallen.

'It probably fell down, too.'

b. weil \{es / das\} wahrscheinlich àuch runtergefallen ist.

One plausible explanation is that speakers come up easily with contexts in which subject referents are interpreted as contrastive topics, as opposed to the referents of other constituents. This would be quite natural, as topics are typically realized as subjects. Another possible reason is that the Contrastive Topic Hypothesis as stated in (15) describes only one part of the association rules for stressed additive particles, and has to be supplemented by a second rule saying that the associated constituent may also be the subject of the clause in which the particle occurs. Such a dis junctive rule could also be motivated by the fact that topics are typically subjects; a rule that initially identified contrastive topics may have been generalized to include subjects. But notice that even if the associated constituent is a subject, the type of context that comes to mind is one in which the subject has the role of a contrastive topic. We can reproduce the case illustrated with example (17):
A: Ich sehe, Tante Anna ist gekommen. Ist sonst noch wer gekommen? 'I see that Aunt Anna came. Did anyone else come?'
B: Auch ein Vertrèter ist gekommen.
'Also a salesman came.'
B': 'Ein /Vertréter ist àuch gekommen. 
A's question presupposes that someone else arrived. It can be answered with (B). The answer ( $\left.\mathrm{B}^{\prime}\right)$ sounds considerably less natural, presumably because the context of A cannot easily be enriched to one in which Aunt Anna and an unspecified salesman form elements of the same class of potential topics. This argues against the assumption that simple subjecthood qualifies for association with postposed stressed auch. The associated constituent must be a contrastive topic.

\title{
2.6 Non-Overt Associated Constituents
}

There are cases in which the associated constituent of a stressed additive particle is not overt, but phonologically empty. Such examples have been reported by Altmann (1976: 261), Taglicht (1984), Kowalski (1992) and Heim (1992).

\author{
a. Komm bitte àuch! \\ 'come please, too!' \\ b. Er bat sie, PRO àuch zu kommen. \\ 'He asked her to come, too'
}

Notice that (32.a) presupposes that someone else besides the addressee will come, so it is the addressee that auch associates with. But as usual with imperatives, the addressee remains phonologically unspecified. In (32.b), auch does not associate with sie. This meaning would be expressed by Er bat sie àuch, morgen zu kommen 'He asked her, too, to come tomorrow'. This presupposes that he asked someone else to come tomorrow, which is not a presupposition of (32.b). Rather, auch has to associate with the implicit subject of the infinitive phrase, typically assumed to be an empty anaphoric element, PRO. This gives us the intended meaning, namely, that it is presupposed that someone else will come tomorrow, and that he expressed the following wish towards her: That she, too, should come tomorrow.

The examples we have seen so far contained a non-overt associate of auch in subject position. We also find non-overt associates in other syntactic positions, as the following examples illustrate. Here the associate is an implicit temporal argument and a non-overt object.

\section{a. A: Letzes Jahr hatten wir schlechtes Wetter beim Betriebsausflug.} Und dieses Jahr?

'Last year the weather was bad when we had our department excursion. And this year?'

B: Es hat àuch geregnet.

'It rained as well'

b. A: Du hast das Geschirr gespült. Und den Abfall?

'You did the dishes. And the garbage?'

B: Hab ich àuch erledigt. 'I took care (of it) too.'

In all these cases the point can be made that the non-overt constituent has the role of a contrastive topic. One might doubt this in the case of (32.b), as the presumed topic would occur embedded in a sentence. However, notice that topics (and contrastive topics) can occur in embedded sentences:

Sie bestand darauf, daß Péter morgen àuch kommen sollte.

'She insisted that Peter should come tomorrow, too.'

Non-overt elements as associates of stressed additive particles are particularly interesting, as contrastive focus marking cannot be expressed with them at all - prosodic features like pitch and amplitude need some phonetic material to be realized. But these cases are similar to the cases of non-stressed pronouns that we 
discussed in section 2.5. It seems that contrastive topichood need not be expressed in the sentence in which the stressed additive particle occurs, it is sufficient that the associate satisfies the role of a contrastive topic in the context in which the sentence occurs.

\subsection{Stressed Additive Particles as Contrastive Topic Indicators}

We have seen with a number of examples that postposed stressed additive particles naturally associate with a constituent that is a contrastive topic of their clause. We also have seen cases in which the associate need not be marked as a contrastive topic. This suggests that stressed additive particles may be able to indicate a contrastive topic without the helping hand of any contrastive topic intonation. A development along the following lines is suggestive: First, contrastive topics can associate with stressed additive particles (I will motivate this below, in section 3). Second, a construction pattem consisting of a clearly marked contrastive topic and a stressed additive particle gets established. Third, the marking of the contrastive topic becomes redundant, to a certain degree, as stressed additive particles occur more or less exclusively with contrastive topics, and the context of utterance can determine which constituent is a contrastive topic. This allows for cases in which the associates of stressed additive particles cannot receive the usual marking as contrastive topics, like weak pronouns and non-overt elements. ${ }^{8}$

The last stage in this sketch describes fairly well what is proposed in a recent treatment of stressed auch, Reis \& Rosengren (1997). It is assumed there that stressed auch is not sensitive to focus, or contrastive topics for that matter. It just indicates that the scope of the particle has to be partitioned into a background and an associated constituent, without indicating how this is to be achieved. The only restriction that stressed auch imposes is that its associate cannot be in the c-command domain of auch, as in this case the associate would receive stress. The stress that auch receives is explained as a default accent: auch cannot be focused, and hence is a good place for an accent if it cannot be realized on any other constituent. This type of default accent is known for so-called verum focus, cf. Höhle (1992)).

I think that Reis \& Rosengren are right in their assumption that the associate of stressed auch need not be marked in any special way. But there are several problems with their approach. First, it is unclear why the associate must have the function of contrastive topic, even if not marked as such (this is a point that Reis \& Rosengren would contest). Second, their account of why auch receives stress is not worked out sufficiently to be convincing; below I will show that auch indeed can receive regular focus. Third, and most importantly, their account does not explain why we do not find exclusive particles like nur and scalar particles like sogar in this pattern. In the following section I will give an explanation of this fact that makes crucial use of the interpretation of these particles and of the nature of contrastive topics.

\section{The Interaction of Contrastive Topics and Grading Particles}

\subsection{Questions and Answers}

In section (2.1) I have characterized the notion of contrastive topic as a constituent that refers to an entity about which information is required at the current point in the discourse, but that there are other entities for which information of a similar type is required. Typically, a stress that identifies a focus within the topic indicates the presence of such alternatives. I will concentrate here on such cases in which contrastive topics are marked overtly. 
The notion of required information can be made more precise by the notion of a question and a congruent answer (cf. Stechow (1990) for this notion). Without going into details (see Groenendijk \& Stokhof (1997) for a recent overview), we can characterize a question meaning by the set of possible answers, as follows (this is essentially the question meaning proposed by Hamblin (1973)):

The meaning of a question [...WH...] is the set of propositions denoted by $[\ldots \alpha . .$.$] , where \alpha$ ranges over the sort of the question constituent WH.

For example, if only two dishes, pasta and polenta, are relevant, then we have the question meaning in (36). In general, these propositions can be rendered as 'Peter ate $\alpha$, where $\alpha$ ranges over meals.

\section{What did Peter eat? \\ \{'Peter ate pasta', 'Peter ate polenta', 'Peter ate pasta and polenta'\}}

A question, then, defines the type of information that is required. It formulates a range of ways how the world could be like, and asks the hearer to cut down these options. This could be done by a simple sentence, like Peter ate pasta, and many question-answer theories have assumed just that. But this is not quite what happens in natural language; instead, we find that focus marking in the answer is used to identify the question it is supposed to answer. The role of focus in the answer is to relate to $\alpha$, the semantic element that identifies the variation and sortal restriction in the construction of the question meaning. The way how focus alternatives relate to question meanings can be described as follows. (As focus can be used in a number of ways, like to associate with particles, I will use the symbol C here to indicate the focus of the comment, which is the focus that identifies the alternatives in answers that correspond to the variation introduced by the question).

A sentence $\left[\ldots C_{F} \ldots\right]$ is a congruent answer to a question meaning $Q$ iff:

a. every alternative [...C'...] of [...C...] entails some proposition in Q;

b. distinct alternatives entail distinct propositions in $\mathrm{Q}$.

According to this definition, the sentence Peter ate pàst $a_{\mathrm{F}}$ is a congruent answer to the question (36). Clearly, Peter ate pasta entails a proposition in the meaning of this question (namely, 'Peter ate pasta'), just as its alternatives (like Peter ate polenta). Furthermore, different altematives entail different propositions in $\mathrm{Q}$. In contrast, Pèter $_{\mathrm{F}}$ ate pasta is not a congruent answer to the question. True, the sentence Peter ate pasta entails a proposition in the question meaning (namely, 'Peter ate pasta'), but its altematives, like Pia ate pasta, do not.

The answer given to a question is typically understood as the most informative true answer, defined as follows: ${ }^{9}$

A congruent answer $\left[\ldots C_{F} \ldots\right]$ is a true exhaustive answer iff

a. [...C...] is true;

b. all alternative answers $\left[\ldots C^{\prime} \ldots\right]$ not entailed by $[. . . C . .$.$] are false.$

In this way, true exhaustive answers eliminate options proposed by the question, thus reducing the informational need expressed by the question. And typically, if a speaker answers a question meaning with a congruent answer, it has to be understood as a true exhaustive answer. This can be motivated by the conversational maxims of Quality and Quantity. ${ }^{10}$ To illustrate, (39.A) has (B) but not (B') as the true exhaustive true answer if Peter indeed ate pasta and polenta.
A: What did Peter eat?
$\mathrm{B}:$ Peter ate $[\text { pásta and polènta }]_{\mathrm{F}}{ }^{11}$
$\mathrm{B}^{\prime}$ : Peter ate pàsta ${ }_{\mathrm{F}}$. 
Why does the focus of the answer have to correspond to the question meaning? It is a marker of discourse coherence. It also allows us to assume that sentences are answers to implicit questions that are indicated by focus:

$$
\text { Peter and Pia went to a restaurant. Peter ate pàsta }{ }_{\mathrm{F}} \text {. }
$$

The focus in the second sentence suggests an implicit question, 'What did Peter eat?', that is a plausible question after the first sentence.

\subsection{Contrastive Topics}

After we have introduced some basic notions of the question-answer relation, let us turn to contrastive topics. Topics are usually analyzed as the entities a predication is "about", arguably the entities with respect to which a piece of information is stored. While this notion of topic may be important, the notion that is more relevant is the background of a sentence with a focus, that is, the "..." part in our representation of such sentences, [.... $\mathrm{C}_{\mathrm{F}} \ldots$... (cf. Stechow (1981)).

The phonological hallmark of a contrastive topic is that we find within the background another expression that is marked by (rising) accent. I will identify this constituent by $\mathrm{T}$, and mark its focus by FT in syntactic representations, to distinguish it from the comment focus. The function of a contrastive topic is to indicate that the answer is partial along the dimension indicated by the contrastive topic. Consider example (41). The question asks about the meals of two persons, but the answer specifies the meals of just one person. The focus within the background, on Peter, indicates the presence of alternative answers, where Peter is replaced by Pia, that would be equally relevant as answers of the question.

\section{A: What did Peter and Pia eat? \\ B: Péter ${ }_{\mathrm{FT}}$ ate pàsta $_{\mathrm{F}}$.}

In which sense is (B) a partial answer? It is certainly not a congruent answer, because it does not entail any of the propositions in the question meaning:
(a) 'Peter ate pasta and Pia ate pasta',
(b) 'Peter ate pasta and Pia ate polenta',
(c) 'Peter ate polenta and Pia ate pasta',
(d) 'Peter ate polenta and Pia ate polenta',
(e) 'Peter ate pasta and polenta and Pia ate pasta',
(f) 'Peter ate pasta and polenta and Pia ate polenta',
(g) 'Peter ate pasta and Pia ate pasta and polenta',
(h) 'Peter ate polenta and Pia ate pasta and polenta',
(i) 'Peter ate pasta and polenta and Pia ate pasta and polenta' \}

But notice that certain propositions in the question meaning entail the sentence Peter ate pasta (namely, a, b, e, f, g, i), and the same holds for its alternatives like Peter ate polenta or Peter ate pasta and polenta. This suggests the following definition:
[... $\left.C_{F} \ldots\right]$ is a partial congruent answer to a question meaning $Q$ iff:
a. for every alternative $C^{\prime}$ to $C$ there is a $p \in Q$ such that $p$ entails [.... $\left.C^{\prime} \ldots\right]$;
b. for every $p \in Q$ there is an alternative $C^{\prime}$ to $C$ s. that $p$ entails $\left[. . . C^{\prime} \ldots ..\right]$;
c. for every two alternatives $C^{\prime}, C^{\prime \prime}$ to $C$ such that $C^{\prime} \neq C^{\prime \prime}$ : $\left\{p \in Q \mid p\right.$ entails $\left.\left[\ldots C^{\prime} \ldots\right]\right\} \neq\left\{p \in Q \mid p\right.$ entails $\left.\left[\ldots C^{\prime \prime} \ldots\right]\right\}$;
d. [...C...] does not entail any proposition in $\mathrm{Q}$.

Condition (a) excludes answers like Peter drank wine $e_{\mathrm{F}}$ as answer to (41.A); the propositions in the question meaning (42) are not entailed by Peter drank wine or its alternatives like Peter drank beer. Condition (b) excludes answers like Pèter $_{\mathrm{F}}$ ate pasta; while the sentence Peter ate pasta Is entailed by certain propositions in the 
question meaning, there are propositions, like (42.d), that do not entail any sentence of the form ' $x$ ate pasta'. Condition (c) says that the alternatives indicated by the focus should make a difference along the dimension indicated by the question. Notice that according to these conditions, congruent answers would count as partial as well; hence a fourth condition, (d), excludes congruent answers explicitly.

What then is the role of the contrastive topic? It specifies answers that would be partial answers as well, but would be entailed by a different set of propositions. For example, the answer Pia ate pasta is entailed by (42.a,c,e,g,h,i), and differs in that from Peter ate pasta.

$\left[\ldots T_{F} \ldots C_{F} \ldots\right]$ is a true contrastive answer to $Q$ iff:

a. $\left[\ldots . . . . C_{F} \ldots\right]$ is a partial congruent answer to $Q$;

b. there are alternatives $T^{\prime}, T^{\prime \prime} \ldots$ to $T$ and alternatives $C^{\prime}, C^{\prime \prime} \ldots$ to $C$ such that $\left[\ldots T . . . C_{F} \ldots\right] \wedge\left[\ldots T^{\prime} \ldots C_{F}^{\prime} \ldots\right] \wedge\left[\ldots T^{\prime \prime} \ldots C^{\prime \prime}{ }_{F} \ldots\right] \wedge \ldots$ entails a true proposition in $\mathrm{Q}$.

Condition (a) excludes answers like Péter ${ }_{\mathrm{FT}}$ drank wine $_{\mathrm{F}}$, but also Pául FT $_{\text {ate pàsta }}$, because they are not entailed by any of the propositions in (42). It also excludes congruent answers like $[\text { Péter and Pía }]_{\mathrm{FT}}$ ate pàst $a_{\mathrm{F}}$, as this would entail a proposition in (42), namely (a), and hence violate the condition of partiality, (43.d). Condition (b) says that by conjoining contrastive answers one can ultimately obtain a complete true answer, one that is entailed by a proposition in the question meaning. For example, conjoining Peter ate pàst $a_{\mathrm{F}}$ with Pia ate polènt $a_{\mathrm{F}}$ leads to a sentence that entails (43.b).

The notion of a contrastive answer does not capture every instance in which a contrastive topic is used. Consider the following example:

\section{A: What did Peter eat? \\ B: Well, Pía ${ }_{\mathrm{FT}}$ ate pàsta ${ }_{\mathrm{F}}$.}

Such cases have been discussed in Hirschberg (1985) as inducing certain implicatures, e.g. that the speaker does not know what Peter ate but that the information that Pia ate pasta may be of relevance for the current informational need expressed by (A). We could perhaps deal with such cases following Büring (1997), whose proposal amounts to the following: The answer (B) indicates that there is an alternative answer that differs in the constituent identified by the contrastive topic accent, and this alternative is a congruent answer to the question. For (B), these alternatives are, of course, sentences like Peter ate pàsta $a_{\mathrm{F}}$ or Peter ate polènta $a_{\mathrm{F}}$. However, this clearly is not sufficient; B's answer only makes sense if we can assume that there is some relation between Pia's eating pasta and the original question, what Peter ate. I will disregard cases like (45) here, as they require a number of additional theoretical assumptions (cf. Merin (1994) for a probability-theoretic account).

\subsection{Disputability and Distinctiveness}

The condition (44.a) for contrastive answers, that the answer given should be a partial and not a complete answer means that there are alternative answers that are logically independent from the answer given. In our example, the answer Peter ate pasta leaves it open what Pia ate. This is the condition of disputability discussed in Büring (1997). It appears to be a natural requirement: After all, contrastive answers introduce alternative topics, and if the answer given were already a complete answer, this additional complexity would be unmotivated.

Büring argues for the disputability condition by showing that it filters out certain scopal readings that otherwise should be available. For example, (46.a) has only the reading in which the negation has wide scope over the quantified NP, corresponding to the underlying structure (ii). The reason is that only (ii) leaves it dis- 
putable for which proportion $\mathrm{p}$ it holds that $\mathrm{p}$ politicians are corrupt (e.g., whether most or some politicians are corrupt). From (i) it follows that the only proportion $\mathrm{p}$ such that $\mathrm{p}$ politicians are not comupt is the one expressed by all (notice that if AL politicians are not corrupt, then it also holds that MOST and SOME politicans are not corrupt), and this violates the disputability condition.

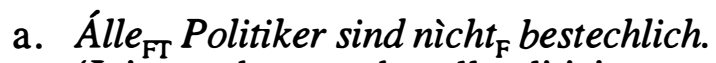

'It is not the case that all politicians are comupt' (= (ii)), not 'For all politicians it holds: They are not corrupt' (= (i))

b. (i) [alle Politiker] ${ }_{1}$ sind $t_{1}$ nicht bestechlich

(ii) [alle Politiker $]_{1}$ sind nicht $t_{1}$ bestechlich

There is another condition that comes with contrastive answers, which I will call distinctiveness. It is a relatively weak condition, but will turn out to be quite important for our purpose.

(47) If $\left[\ldots T_{F} \ldots C_{F} \ldots\right]$ is a contrastive answer to a question $Q$, then there is no alternative $\mathrm{T}^{\prime}$ of $\mathrm{T}$ such that the speaker is willing to assert $\left[\ldots \mathrm{T}^{\prime} \ldots \mathrm{C}\right.$...]..

The reason is that if the speaker could assert $\left[\ldots T^{\prime} \ldots C . ..\right]$, the speaker would have asserted it right away by way of conjoining $T$ and $T^{\prime}$. Condition (47) follows from Grice's maxim of manner, as the answer [...T $\left.\wedge \mathrm{T}^{\prime} \ldots \mathrm{C} . ..\right]$ is shorter than the answer [...T...C...] $\wedge\left[\ldots \mathrm{T}^{\prime} \ldots \mathrm{C} \ldots . ..\right]$. To illustrate, $(48 . \mathrm{B})$ is preferred over $\left(\mathrm{B}^{\prime}\right)$.
A: What did Peter and Pia eat?
B: *Péter ate pàsta, and Pía ate pàsta.
$\mathrm{B}^{\prime}:$ Peter and Pia ate pàsta.
B": Péter ate pàsta, and and Pía ate pasta, tòo.

However, notice that precisely in those cases focus on additive particles is possible (cf. $\left.\mathrm{B}^{\prime \prime}\right)$. It seems that contrastive answers with stressed additive particles allow us to get around the distinctiveness constraint, a point to which I will return.

\subsection{Conjoined Answers and the Problem of the Last Answer}

Questions can be answered by a sequence of contrastive answers, as in (49). The two answers together constitute a complete answer; they entail one of the propositions in the question.

A: What did Peter and Pia eat?
B: Péter
FT
ate pàsta $_{\mathrm{F}}$ and Pía
FT

One way of describing what is going on is to assume that both clauses in B's answer are independent contrastive answers to A's question. The answer Péter $_{\mathrm{FT}}$ ate pàsta $a_{\mathrm{F}}$ leaves it open what Pia did, and the answer Pía $a_{\mathrm{FT}}$ ate polènta $a_{\mathrm{F}}$ leaves it open what Peter did. In a framework of dynamic interpretation this can be understood in the following way. Assume that the update of an information state $c$ with a question $\mathrm{Q}$ is the set of all updates of $c$ with the propositions in $\mathrm{Q}$, that is, $c+\mathrm{Q}=$ $\{c+p \mid p \in Q\}$ (cf. Krifka (1993)). If this set of information states is updated with a congruent answer $A$, then it is reduced to the element that is entailed by $A$; if it is updated with a contrastive answer, then the set of information states is reduced to the disjunction of those that entail the answer. The independent interpretation of contrastive answers amounts to the following: If a context $c$ that is updated with a question $Q$ is answered by a conjunction of two contrastive answers, $A \wedge A^{\prime}$, for which we may write $c+Q+\left[A \wedge A^{\prime}\right]$, then this is computed as the conjunction of $c+Q+A$ and $c+Q+A^{\prime}$. This guarantees that the answers are interpreted separately. However, there is a problem with independent interpretation: The second 
answer can have anaphoric elements that refer to the first answer, which shows that it should be interpreted after the context $\mathrm{c}$ is updated with the first answer.

A: What did the Permaneders eat?

$\mathrm{B}$ : Péter ${ }_{\mathrm{FT}}$ ate pàsta $a_{\mathrm{F}}$ and $[\text { his wífe }]_{\mathrm{FT}}$ ate polènta $a_{\mathrm{F}}$.

This suggests that we compute $c+Q+\left[A \wedge A^{\prime}\right]$ as $c+Q+A+A^{\prime}$. For example, after the first answer in (49.B), the set of propositions in $Q$ is reduced to (42.a,b,e,f,g,i). But this of course makes the second answer dependent on the first. And after the first answer, the second is not contrastive anymore, but rather is a complete answer. In particular, it will entail the proposition (42.b). In a sense, the last answer completes the answer and therefore cannot be partial, if the preceding partial answers were already added to the information state.

We can overcome this dilemma by assuming that answers are interpreted sequentially, but each answer has to satisfy the criterion posed by the question independently. Let me write $c+A / Q_{c}$ for $c$ updated with $A$, provided that $A$ is a (coherent or partial) answer to $Q$ uttered in context $c$. Then $c+\left[A \wedge A^{\prime}\right] / Q_{c}$ should be computed as $c+A / Q_{c}+A^{\prime} / Q_{c}$. In (50), both answers are partial answers to the question, but the second is interpreted at an information state that is updated with the first.

\subsection{Contrastive Topics + Stressed Additive Particles}

Let us now return to the interpretation of sentences with stressed additive particles. The following example makes the context explicit in which they are typically used:

\section{A: What did Peter and Pia eat? \\ B: Péter ate pàsta, and Pía ate pasta, tòo.}

If we take the accentuation pattem seriously, we must assume that the second clause of (B) does not answer the question (A) directly, but that it answers a related question that indirectly leads to an answer of (A). Which one? A plausible candidate is Did Pia eat pasta? But for such a question the contrastive topic accent on Pia would be unmotivated. So, the implicit question is rather Did Peter and Pia eat pasta? One part of this question is already answered by the first clause of (B), but some options still remain open, and this motivates the contrastive topic accent. Notice that explicit question-answer sequences of this type are quite natural (cf. (52.A,B)):
A: Did Peter and Pia eat pasta?
B: Péter $r_{\mathrm{FT}}$ ate pàsta, and Pía ${ }_{\mathrm{FT}}$ ate pasta, tòo.

In (35) we have discussed constituent questions. (52.A) is an example of a polarity question. For our purposes we can assume that the meaning of such questions consists of a proposition and its negation, as in the following example:

$$
\begin{aligned}
& \text { Did Peter eat pasta? } \\
& \text { \{'Peter ate pasta', 'Peter didn't eat pasta'\} }
\end{aligned}
$$

As with constituent questions, we expect that the focus of the answer identifies the alternatives. This suggests that an element that affirms or denies the proposition should be in focus. This is plausible for negated answers, where the negation element didn't receives the main stress (cf. (54.a)). But in the case of a positive answer we find that stress can go on content words, like the object NP in (b). Accent can also go to a periphrastic do, to an auxiliary, or to a modal particle expressing the strength of the assertion (cf. c,d). This presumably identifies an affirmative element, but is also understood as emphatic, suggesting that the speaker has reason to believe that the hearer is inclined to believe that Peter didn't eat pasta. 

a. (No,) Peter didn't eat pasta.
b. (Yes,) Peter ate pàsta.
c. (Yes,) Peter did eat pasta.
d. (Yes,) Peter cèrtainly ate pasta.

The neutral pattern in (54.b) can be accounted for by assuming that the affirmative element is non-overt, and hence cannot be marked by stress. The stress pattem, then, is the one we find when focus is absent (cf. Jacobs (1992)). In the case at hand the stress rules predict that the stress is realized on the object of the verb. For the marked patterns in (54.c,d) we either assume that the stressed constituent is or contains the affirmative element, or that accent is realized there by default (cf. Höhle 1992 for this latter assumption in the case of (c)).

In the first clause of (52.B) we have an affirmative answer to a polarity question with a contrastive topic. To be specific, we can assume the following structure, where the implicit affirmative element is made explicit and is the focus of the answer (but notice that there is no particular reason to place AFF at the end).

$$
\text { Péter }_{\mathrm{FT}} \text { ate pàsta } \mathrm{AFF}_{\mathrm{F}} \text {. }
$$

According to our usual interpretation of contrastive answers, this indicates that the answer is partial insofar as it does not answer the question for alternatives of Peter. To be more specific, the question (52.A) denotes the following set of propositions, of which (a) and (b) entail the answer (55)
Did Peter and Pia eat pasta?
\{ (a) 'Peter ate pasta and Pia ate pasta',
(b) 'Peter ate pasta and Pia didn't eat pasta',
(c) 'Peter didn't eat pasta and Pia ate pasta',
(d) 'Peter didn't eat pasta and Pia didn't eat pasta' \}

I would like to propose that stressed additive particles receive their stress in those contexts because they realize an affirmative element explicitly, just like did and certainly in (54.c,d). Additive particles contrast with the non-overt affirmative element AFF and hence expresses a particular emphasis. This special emphasis is motivated, as the first answer of (52.B) suggests that Pia did not eat pasta, due to the condition of distinctiveness (47).

What are the alternatives to ADD? Recall the meaning rule for ADD in (2.a). The asserted part consists of [...F...], that is, it states that the sentence with the focus item $F$ is indeed true. The only plausible alternative to that is that $[\ldots F . .$.$] is$ not true, that is, $\neg[\ldots F . .$.$] . That this is indeed an alternative is evident from the$ fact that instead of (52.B) we could have the following answer:

$$
\mathrm{B}^{\prime} \text { : Péter }{ }_{\mathrm{FT}} \text { ate pàsta } \mathrm{AFF}_{\mathrm{F}} \text {, but Pía } a_{\mathrm{FT}} \text { didn't } t_{\mathrm{F}} \text { eat pasta. }
$$

ADD also contains a presuppositional part, and the null hypothesis is that the altematives of ADD all have the same presupposition. The proper altemative to ADD then would be ADD*, defined as follows:

$$
\left[\mathrm{ADD}^{*}{ }_{1}\left[\ldots \mathrm{F}_{1} \ldots\right]\right]=\neg\left[\ldots \mathrm{F}_{1} \ldots\right]\left(\exists \mathrm{F}^{\prime} \neq \mathrm{F}\left[\ldots \mathrm{F}^{\prime} \ldots\right]\right)
$$

But there is a problem with this analysis: It entails that EVERY altemative predication comes with the existential presupposition. For example, the contrastive topic on Pia in the second answer in (52.B) indicates that there are altematives like 'Peter ate pasta (in addition to someone else)', or 'Peter didn't eat pasta (but someone else did)'. The problem is that the existential presupposition is not satisfied for these altematives, as after the first clause it is not guaranteed that someone else than Peter ate pasta. If we compute the meaning along the scheme $c+Q+\left[A \wedge A^{\prime}\right]=c+A / Q_{c}$ $+A^{\prime} / Q_{c}$, then this problem can be expressed as follows: In the context in which the 
second answer, $A^{\prime}$, is asserted (that is, in $c+A / Q_{c}$ ), its existential presupposition is satisfied by the first answer, $A$. But the alternative of $\mathrm{A}^{\prime}$, which corresponds to $\mathrm{A}$ except it has an existential presupposition, could not be uttered here, as its existential presupposition is not satisfied in this context.

We therefore have to assume that the alternatives of ADD can also be simple affirmation and negation, [...F...] and $\neg[\ldots . . .$.$] . The way how sentences with$ stressed additive particles are to be analyzed then can be illustrated as follows:

$\left[P i a_{\mathrm{F} 1}\right]_{\mathrm{FT}}$ ate pasta, $[\text { tòo }]_{\mathrm{F}}$

In this analysis, Pia is the associated constituent of too, and the contrastive topic of the sentence. The comment focus is on too. According to our rule for true contrastive answers (44) this is interpreted as follows:

a. Pia ${ }_{\mathrm{F} 1}$ ate pasta, $\left[\text { tòo }_{1}\right]_{\mathrm{F}}$ is a partial answer to (52.A);

b. there are distinct alternatives to Pia (in this case, Peter), such that there are alternatives $C$ to $t o o$, such that the conjunction of Pia $_{\mathrm{F} 1}$ ate pasta too ${ }_{1}$ and Peter $_{\mathrm{F} 1}$ ate pasta $C_{1}$ entails a true proposition in (52.A).

These conditions are satisfied. First, (59.a) amounts to the proposition 'Pia ate pasta', with the presupposition that someone else ate pasta, which is satisfied after the first part of the answer, Peter ate pasta. This proposition is a partial answer to (52.A) $(=(56))$, as it is entailed by $(56 . \mathrm{a}, \mathrm{c})$. As for (59.b), notice that the alternative answers Peter ate pasta AFF or Peter did nòt eat pasta would lead to a complete answer that entails the proposition (56.a) or (56.c), respectively. Recall that these alternatives are evaluated irrespective of the fact that the first alternative, Peter ate pasta, actually has been given already.

One question at this point is why too is necessary in the answer (cf. (52.B")

The reason for that is the distinctiveness condition, (47). The answer (52.B" would be preferred by the maxim of manner. The use of too allows to violate distinctiveness by explicitly stating a discourse relation.

$$
\begin{aligned}
& \mathrm{B}^{\prime \prime}: \text { ?? Péter ate pàsta and Pía ate pàsta. } \\
& \mathrm{B}^{\prime \prime \prime} \text { : Peter and Pia ate pàsta. }
\end{aligned}
$$

\subsection{Why no Exclusive or Scalar Particles?}

One of our initial observations was that exclusive particles do not occur in the same pattern as additive particles. Assume for the sake of the argument they could:

$$
*\left[\text { Pía }_{\mathrm{F} 1}\right]_{\mathrm{FT}} \text { ate pasta, }\left[\text { ònly }_{1}\right]_{\mathrm{F}} \text {. }
$$

As this is a contrastive answer, the sentence Pía $a_{\mathrm{FT}}$ ate pasta, $\left[\text { ònly }_{1}\right]_{\mathrm{F}}$ must be a partial answer to its question. It is not quite clear what the question could be. When we recall the meaning of exclusive particles given in (2.b), then it should be something like 'Did Peter and Pia (each) eat pasta all by themselves, or in addition to other people?' Now, the answer given states that only Pia ate pasta. But this already answers the question, in a sense, for Peter as well: If only Pia ate pasta, then Peter certainly did not eat pasta, and the question whether or not he was the only one does not even arise. So the disputability condition explains why (60) is bad.

What about scalar particles? I have suggested an interpretation of scalar particles in (2.c). Why then is the following sentence bad?

$$
*\left[\text { Pía }_{\mathrm{F} 1}\right]_{\mathrm{FT}} \text { ate pasta, }[\text { èven }]_{\mathrm{F}} \text {. }
$$


This follows from a general fact about scalar particles. They can never be stressed, that is, they can never be the focus of an operator (except in meta-linguistic, correctional contexts). For example, observe the following contrast:
a. I didn't think that Pia would come, but then ònly she was there.
b. *I didn't think that Pia would come, but then èven she was there.

In Krifka (1992) I suggested the following reason for this difference. Particles like even do not associate directly with a focus. They rather mark the assertion or other illocutionary act in which they occur as emphatic. It is the illocutionary operator itself that then associates with a focus, and this operator cannot be in the scope of another operator. This explains, among other things, why even can extend its scope in ways that are not possible for focus-sensitive particles. Example:

a. The presence of even [the high priest $]_{\mathrm{F}}$ is required in this ceremony. $\Leftrightarrow$ Even the presence of $[\text { the high priest }]_{\mathrm{F}}$ is required in this ceremony.

b. The presence of only [the high priest $]_{\mathrm{F}}$ is required in this ceremony. $\Leftrightarrow$ Only the presence of [the high priest $]_{\mathrm{F}}$ is required in this ceremony.

Notice that the (b) sentences are not equivalent insofar as the first one disallows that other priests are present, which the second one doesn't. No comparable difference exists for the (a) sentences. This can be explained by assuming that in (a), the scope of the operator that exploits the focus information is always the whole sentence, which follows if this is the illocutionary operator.

\section{Conclusion}

In this paper I have argued that the associated constituent of stressed additive particles like too is a contrastive topic of a sentence. This is often but not necessarily identified by the prosodic pattern characteristic of contrastive topics. The comment focus is on the particle itself, which is marked in the usual way, by accent. It is an alternative to the simple affirmation and negation of the sentence. One important condition for sentences with contrastive topics is disputability, which says that the sentence must not fully decide the issue for all alternatives of the contrastive topic. This is compatible with additive particles, but not with exclusive particles like only, which explains why they do not occur in this pattern: They violate this criterion, as they give a complete answer to their question. Scalar particles, like even, express emphasis and cannot stand in any alternative relation to other operators.

\section{Endnotes}

* I began working on this article when I was a fellow at the Institute for Advanced Studies at the Hebrew University of Jerusalem, and finished it as a guest at the Max Planck Institute for Psycholinguistics in Nijmegen. I thank these institutions for their support. I thank Thomas Becker, Daniel Büring, Zuzana Dobes, Edit Doron, Caroline Féry, Veerle van Geenhoven, Petra Gretsch, Gerhard Jäger, Wolfgang Klein, Knud Lambrecht and Marga Reis for discussions of various topics relating to this article. I wish to dedicate this article to the memory of Carl Lee Baker, colleague, friend and closet semanticist. He once confided to me that he would faint whenever he sees a lambda, so I tried to write an article without one. I hope that he would have liked the result.

${ }^{1}$ Reis \& Rosengren (1997) assume more specifically that the assertional part "adds" a meaning [...F...] that is of the same type as the one that is presupposed, that is, 
of the type [...X...]. This adding operation could be understood in a framework of dynamic semantics as regular update of a common ground.

${ }^{2}$ More colloquially, this is expressed by a syntactic construction, like $\mathrm{Ce}$ n'est que Marie qui est venue.

${ }^{3}$ The sentence is fine with the meaning 'Marie came alone'.

${ }^{4}$ Altmann (1976) and Jacobs (1983) discuss this pattern only with nur and sogar, and Reis \& Rosengren (1997) assume that this pattern is not possible for auch. However, a question like Wer hat sonst noch die Ausstellung besucht? 'Who else visited the exhibition' can be answered by Pèter hat auch die Ausstellung besucht.

${ }^{5}$ In its emphatic use selbst is fine here, with the interpretation 'Peter visited the exhibition himself'.

${ }^{6}$ This pattern was identified by Jackendoff (1972) with examples like What about Fred? What did he eat? - Fréd ate the beàns. Pierrehumbert \& Hirschberg (1990) argue that the rise accent is to be analyzed as $\mathrm{L}+\mathrm{H}^{*}$ in English and has a contrastive meaning, as opposed to the fall accent, which they analyze as $\mathrm{H}^{*}$ and as conveying newness. For German, Féry (1993) argues for a combined $\mathrm{L}^{*} \mathrm{H}-\mathrm{H}^{*} \mathrm{~L}$ contour that is distinct from the contour we find with multiple foci, while Jacobs (1997) argues that the rise accent is a slight fall followed by a rise. The notion of "contrastive topic" corrresponds to what Büring (1998) calls "S-topic"; Büring's own notion of contrastive topic applies to examples like (45).

${ }^{7}$ The sentence is fine if too associates with soup only (meaning 'Jo had fish, and Mo had fish and soup, too'.

${ }^{8}$ It should be noticed that we do not even need the presence of a stressed additive particle to identify a constituent as contrastive topic in the absence of contrastive topic marking. Consider the following variant of (33.b): A: You did the dishes, but what about the garbage? - B: Muß ich noch machen. 'I still have to do (it)'. Arguably, the empty object NP is a contrastive topic here just as in (33.b), but this is neither indicated by prosodic marking, nor by stressed auch.

${ }^{9}$ This definition depends on the world of evaluation, due to the reference to true sentences. We can arrive at a more general notion of exhaustive answer by abstracting over this parameter.

${ }_{10}$ There are other ways of giving information in the dimension required by the question. In particular, certain options can be excluded. For example, the question What did Peter eat? can be answered by Peter didn't eat pàsta ${ }_{\mathrm{F}}$. However, I will concentrate here on the standard case of congruent answers.

${ }^{11}$ The rise on pasta is not quite the same as with contrastive topics. See Féry (1993) for the realization of multiple accents in German.

\section{References}

Altmann, Hans. 1976. Die Gradpartikel im Deutschen. Tübingen: Niemeyer.

Büring, Daniel. 1997. The great scope inversion conspiracy. Linguistics and Philosophy 20, 175-194.

Büring, Daniel. 1998. The 59th Street Bridge Accent. London: Routledge.

Féry, Caroline. 1993. German intonational patterns. Tübingen: Niemeyer.

Green, Georgia 1973. On too and either, and not ust too and either, either, Chicago Linguistic Society, Vol. 4 22-39.

Groenendijk, Jeroen and Martin Stokhof 1997. Questions. In Johan van Bentham and Alice ter Meulen (eds.), Handbook of logic and language 1055-1124. Amsterdam: Elsevier.

Hamblin, C.L. 1973. Questions in Montague grammar. Foundations of Language 10, 41-53. 
Heim, Irene. 1992. Presupposition projection and the semantics of attitude verbs. Journal of Semantics 9, 183-222.

Hirschberg, Julia 1985. A theory of scalar implicature. Ph.D. diss., University of Pennsylvania.

Höhle, Tilman 1992. Über Verum-Fokus im Deutschen. In Joachim Jacobs (ed.), Informationsstruktur und Grammatik 112-141. Opladen: Westdeutscher Verlag.

Horn, Lawrence 1969. A presuppositional analysis of only and even, Papers from the fifth regional meeting, Chicago Linguistic Society 318-27.

Jackendoff, Ray. 1972. Semantic Interpretation in Generative Grammar. Cambridge, Mass.: MIT Press.

Jacobs, Joachim. 1983. Fokus und Skalen. Zur Syntax und Semantik der Gradpartikel im Deutschen. Tübingen: Niemeyer.

Jacobs, Joachim 1992. Neutral stress and the position of heads. In Joachim Jacobs (ed.), Informationsstruktur und Grammatik 220-244. Opladen: Westdeutscher Verlag.

Kaplan, Jeff. 1984. Obligatory too in English. Language 60, 510-518.

Koktová, Eva. 1987. On the scoping properties of negation, focusing particles and sentence adverbials. Theoretical Linguistics 14, 173-226.

König, Ekkehart. 1991. The meaning of focus particles. A comparative perspective. London, New York: Routledge.

Kowalski, A. 1992. Zur Syntax und Semantik von Gradpartikeln im Deutschen. Syntaktische Bedingungen für die Ausdehnung von Partikelskopus und fokus. M.A. Thesis, University of Wuppertal.

Krifka, Manfred. 1992. A compositional semantics for multiple focus constructions. In J. Jacobs (ed.), Informationsstruktur und Grammatik. . 17-53. Opladen: Westdeutscher Verlag.

Krifka, Manfred. 1993. Focus and presupposition in dynamic interpretation. Journal of Semantics 10, 269-300.

Merin, Arthur 1994. Why not Kim Basinger? On the 'Art des Gegebenseins' of a contextually given set. Hans Kamp and Barbara Partee (eds.), Contextdependence in the analysis of linguistic meaning, Vol. I 291-310. Prague and Bad Teinach: Institut für maschinelle Sprachverarbeitung, University of Stuttgart.

Pierrehumbert, Janet and Julia Hirschberg. 1990. The meaning of intonational contours in the interpretation of discourse, Intentions in communication 271-311. Cambridge, Mass:: MIT Press.

Reis, Marga and Inger Rosengren 1997. A modular approach to the grammar of additive particles: the case of German auch. Ms., University of Tübingen. To appear in Journal of Semantics.

Stechow, Amim von. 1981. Topic, focus, and local relevance. In Wolfgang Klein and Willem Levelt (eds.), Crossing the Boundaries in Linguistics. Dordrecht: Reidel.

Stechow, Amim von. 1990. Focusing and backgrounding operators. In Werner Abraham (ed.), Discourse particles 37-84. Amsterdam: John Benjamins.

Taglicht, Josef. 1984. Message and emphasis: On focus and scope in English. London: Longman. 